\title{
Electrical impedance tomography to determine optimal positive end-expiratory pressure in severe chronic obstructive pulmonary disease
}

\author{
Eirini Kostakou* (D), Nicholas Barrett and Luigi Camporota
}

Keywords: Chronic obstructive pulmonary disease, Electrical impedance tomography

Dynamic hyperinflation (DH) is a consequence of severe airflow obstruction in patients with asthma and chronic obstructive pulmonary disease (COPD). Incorrect setting of positive end-expiratory pressure (PEEP) can lead either to unopposed intrinsic PEEP (iPEEP) (when set too low) or to an increase in lung volume if PEEP is set above iPEEP. DH and iPEEP can lead to haemodynamic compromise [1], increased work of breathing and asynchrony [2]. PEEP setting is challenging because iPEEP is clinically difficult to quantify. Electrical impedance tomography (EIT) provides information on the temporal and spatial heterogeneity of ventilation [3]. EIT may prove useful in optimizing PEEP to overcome gas trapping and DH [4]. We present a method in which the use of EIT allowed selection of PEEP to provide the least DH and inhomogeneity of lung mechanics.

A patient with severe acute COPD exacerbation was on pressure control ventilation: $\mathrm{FiO}_{2}$ 0.25, PEEP 10 $\mathrm{cmH}_{2} \mathrm{O}$, peak pressure $28 \mathrm{cmH}_{2} \mathrm{O}$, tidal volume $515 \mathrm{ml}$, I:E 1:4.4 and set frequency 14/min using an Evita XL ventilator (Draeger-Luebek, Germany). After a short period, the patient developed worsening hypercapnia and clinical evidence of DH. Subsequently a PEEP titration using EIT (Pulmovista'; Draeger-Luebek) was performed to optimize ventilator settings with the aim of minimizing DH.

The patient remained sedated, paralysed and in a supine position throughout the PEEP titration. We

\footnotetext{
* Correspondence: ekostakou@yahoo.com

Department of Adult Critical Care, Guy's and St Thomas' NHS Foundation

Trust, King's Health Partners, St Thomas' Hospital, 1st Floor East Wing,

Westminster Bridge Road, London SE1 7EH, UK
}

measured static iPEEP and compliance using endinspiratory and end-expiratory hold manoeuvres. iPEEP was measured in a range of set external PEEP, and the iPEEP was calculated as total PEEP minus set PEEP. EIT, tidal volumes, trapped gas volumes and ventilator pressures were then measured at PEEP set to $0 \%, 50 \%$, $80 \%, 100 \%$ and $150 \%$ of iPEEP.

EIT waveforms were analysed offline to determine ventilation heterogeneity at different levels of applied PEEP corresponding to $50 \%, 80 \%, 100 \%$ and $150 \%$ of the static iPEEP. We measured the regional delay of ventilation as a marker of homogeneity of ventilation [5]. We compared this index with oesophageal pressure, with static and dynamic compliance and with arterial blood gases.

EIT allowed determination of the level of PEEP able to achieve greatest lung homogeneity. This level of PEEP was $80 \%$ of iPEEP (Fig. 1). This value also achieved the highest expired tidal volume and the lowest airway resistance. Lung mechanics suggest that PEEP between 80 and $100 \%$ of iPEEP achieves the best compromise between total PEEP and trapped volume (Table 1).

This case illustrates how EIT may be useful in assessing regional ventilation and suggesting optimal PEEP. Through optimizing conventional ventilation, bedside EIT may guide ventilatory strategy to reduce hyperinflation, reduce dead space and hence reduce asynchrony and work of breathing without the need for more invasive procedures. 


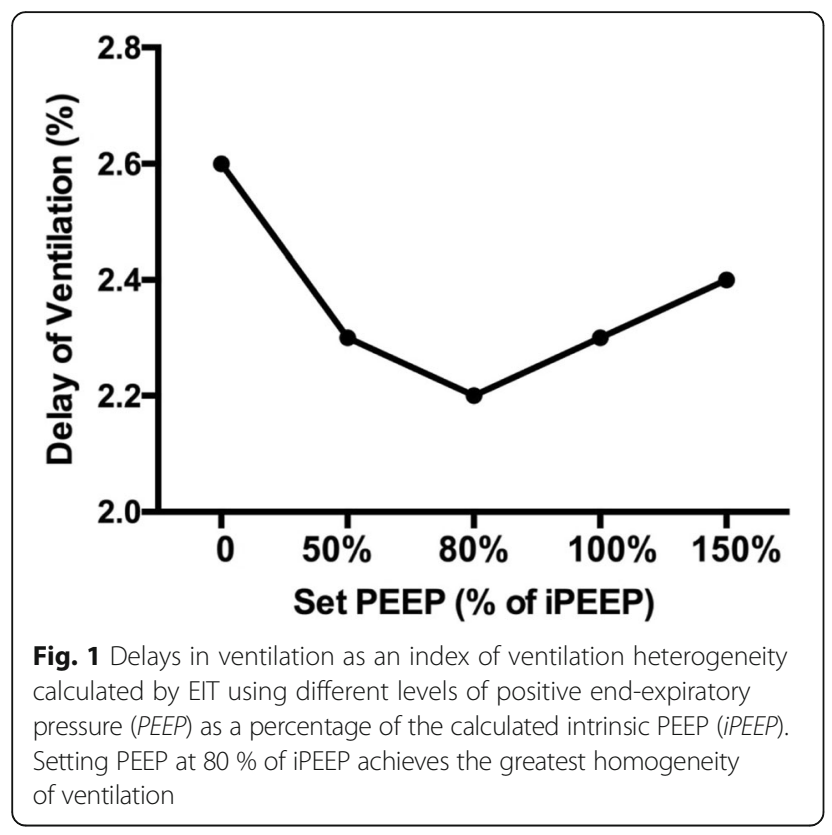

Table 1 Measurements of lung mechanics at different PEEP levels

\begin{tabular}{llllll}
\hline & ZEEP & $\begin{array}{l}50 \% \\
\text { iPEEP }\end{array}$ & $\begin{array}{l}80 \% \\
\text { iPEEP }\end{array}$ & $\begin{array}{l}100 \% \\
\text { iPEEP }\end{array}$ & $\begin{array}{l}150 \% \\
\text { iPEEP }\end{array}$ \\
\hline Set PEEP $\left(\mathrm{cmH}_{2} \mathrm{O}\right)$ & 0 & 5 & 8 & 10 & 15 \\
$\begin{array}{l}\text { PEEP tot measured } \\
\left(\mathrm{cmH}_{2} \mathrm{O}\right)\end{array}$ & 10 & 10 & 11 & 11 & 15 \\
$\begin{array}{l}\text { Plateau pressure } \\
\left(\mathrm{cmH} \mathrm{H}_{2} \mathrm{O}\right)\end{array}$ & 18 & 21 & 20 & 19 & 21 \\
$\begin{array}{l}\text { Expired tidal volume } \\
(\mathrm{ml})\end{array}$ & 505 & 515 & 515 & 500 & 372 \\
$\begin{array}{l}\text { Static compliance } \\
\left(\mathrm{ml} / \mathrm{cmH} \mathrm{H}_{2} \mathrm{O}\right)\end{array}$ & 63 & 47 & 57 & 62.5 & 62 \\
\begin{tabular}{l} 
Trapped volume $(\mathrm{ml})$ \\
\hline
\end{tabular} & 390 & 350 & 150 & 80 & 0 \\
\hline
\end{tabular}

ZEEP zero end-expiratory pressure, iPEEP intrinsic positive end-expiratory pressure, $P E E P$ positive end-expiratory pressure

\section{Abbreviations}

COPD: Chronic obstructive pulmonary disease; DH: Dynamic hyperinflation; EIT: Electrical impedance tomography; iPEEP: Intrinsic positive end-expiratory pressure; PEEP: Positive end-expiratory pressure; ZEEP: Zero end-expiratory pressure

\section{Authors'contributions}

EK, NB and LC designed and participated in drafting the manuscript. EK and LC approved the final version. All authors read and approved the final manuscript.

\section{Competing interests}

$L C$ received speaking honoraria from Draeger. NB receives research and educational funding from Draeger, ALung, Maquet, Corpak, Fisher \& Paykel and Mitsubishi-Tanabe Pharmaceuticals. EK declares that they have no competing interests.

\section{Declaration of interests}

EK is in a clinical research fellowship funded by ALung Technologies Incorporated. LC and NB have no personal financial interests to disclose.

Received: 30 May 2016 Accepted: 30 August 2016

Published online: 22 September 2016

\section{References}

1. Brandolese R, Broseghini C, Polese G, Bernasconi M, Brandi G, Milic-Emili J, Rossi A. Effects of intrinsic PEEP on pulmonary gas exchange in mechanically-ventilated patients. Eur Respir J. 1993;6(3):358-63.

2. Laghi F, Goyal A. Auto-PEEP in respiratory failure. Minerva Anestesiol. 2012; 78(2):201-21.

3. Vogt B, Pulletz S, Elke G, Zhao Z, Zabel P, Weiler N, Frerichs I. Spatial and temporal heterogeneity of regional lung ventilation determined by electrical impedance tomography during pulmonary function testing. J Appl Physiol. 2012;113:1154-61. doi:10.1152/japplphysiol.01630.2011.

4. Mauri T, Bellani G, Salerno D, Mantegazza F, Pesenti A. Regional distribution of air trapping in chronic obstructive pulmonary disease. Am J Respir Crit Care Med. 2013:188:1466-7. doi:10.1164/rccm.201303-0463IM.

5. Muders T, Luepschen H, Zinserling J, Susanne Greschus S, Fimmers R, Guenther U, Buchwald M, Grigutsch D, Leonhardt S, Putensen C, Wrigge H. Tidal recruitment assessed by electrical impedance tomography and computed tomography in a porcine model of lung injury. Crit Care Med. 2012:40(3):903-11. doi:10.1097/CCM.0b013e318236f452. 